\title{
PERENCANAAN RESAPAN AIR SEBAGAI ALTERNATIF PENANGGULANGAN BANJIR DI MAN 1 SUMBAWA
}

\author{
TRI SATRIAWANSYAH \\ Dosen Program Studi Teknik Sipil Fakultas Teknik Universitas Samawa (UNSA) Sumbawa Besar
}

\begin{abstract}
ABSTRAK
Di Kota Sumbawa khususnya di kawasan MAN 1 Sumbawa sering dihadapkan dengan fenomena genangan banjir dan secara rutin menggenangi kawasan tersebut. Kedalaman air akibat banjir bisa mencapai $20-50 \mathrm{~cm}$ dengan luas genangan $1.701 \mathrm{~m} 2$. Sumur resapan yang tersedia di kawasan MAN 1 Sumbawa dinilai kurang maksimal dalam menanggulangi banjir. Dikarenakan jumlahnya hanya 1 (satu) sehingga tidak bisa menanggulangi debit banjir yang ada. Penelitian ini bertujuan untuk mengatasi genangan di MAN 1 Sumbawa. Penelitian dilakukan dengan metode deskriptif kuantitatif. Penelitian berlokasi di kawasan MAN 1 Sumbawa Jl.Kepiting no.69 Kelurahan Seketeng kecamatan Sumbawa. Prosedur penelitian : persiapan, pelaksanaan, pengambilan data serta analisis data. Hasil penelitian menunjukkan bahwa dimensi sumur resapan hasil perencanaan diperoleh diameter $1.5 \mathrm{~m}$ dan kedalaman $2 \mathrm{~m}$ dengan jumlah sumur resapan sebanyak 4 buah dengan jarak 7.5 meter. Dengan perencanaan 4 buah sumur resapan pada lahan MAN 1 Sumbawa akan bisa menanggulangi genangan yang terjadi pada musim hujan dengan lama menyerap air ke dalam tanah 0,85 jam atau 51 menit. Hasil dari perencanaan untuk LRB diperoleh dimensi dengan diameter $10 \mathrm{~cm}(0,1 \mathrm{~m})$ dan kedalaman $100 \mathrm{~cm}(1 \mathrm{~m})$ dengan jumlah pekerjaan LRB sebanyak 12 buah dengan jarak 6 meter. Dengan perencanaan 12 buah LRB bisa melindungi system air tanah (ground water system) pada kawasan MAN 1 Sumbawa Besar. Bagi lingkungan pendidikan MAN 1 Sumbawa agar membangun sumur resapan dan lubang resapan biopori. Bagi pemerintah terkait, yakni Dinas Pendidikan Kabupaten Sumbawa agar segera membangun sumur resapan dan lubang resapan biopori di kawasan MAN 1 Sumbawa. Bagi mahasiswa dan akademisi sebagai referensi untuk penelitian-penelitian selanjutnya yang berhubungan dengan masalah penanggulangan banjir. Bagi peneliti selanjutnya agar mengkombinasi sumur resapan dengan menambahkan isi didalamnya berupa ijuk, batu gosong sebagai penyerap.
\end{abstract}

Kata Kunci : Banjir, MAN 1, Sumur Resapan, Lubang Resapan Biopori

\section{PENDAHULUAN}

Tingginya tingkat curah hujan di Kota Sumbawa Besar dari tahun ke tahun telah banyak menimbulkan dampak kerugian dalam segala aspek. Kenyamanan bagi masyarakat dalam melaksanakan aktifitas seperti pekerjaan, sekolah serta rutinitas sehari-hari sangatlah terganggu. Semakin cepatnya laju pembangunan yang tidak lagi terkontrol membuat tanaman kota tidak lagi rapi mengakibatkan semakin sempitnya wilayah resapan air dan juga penyempitan saluran-saluran pembuangan air seperti selokan serta sungai.

Curah hujan yang tinggi di wilayah kota Sumbawa Besar menyebabkan mengumpulnya air semakin banyak dan banyak menimbulkan genangan di beberapa titik hal ini dikarenakan kurangnya daerah resapan air.
Terutama di kawasan Sekolah Madrasah Aliyah Negeri (MAN) 1 Sumbawa Besar yang merupakan kawasan yang sangat vital, karena kawasan tersebut merupakan tempat melakukan peroses belajar mengajar tempat menimba ilmu bagi para pelajar para penerus estapet pemimpin bangsa.

Maka dari itu sekolah MAN 1 Sumbawa Besar merupakan kawasan yang diutamakan tidak boleh tergenang oleh air hujan atau bila terdapat genangan agar diminimalkan kemungkinan tersebut. Perlu adanya penanganan cepat apabila terjadi banjir maupun genangan di sekolah MAN 1 Sumbawa Besar, sehingga dapat meminimalkan dampak dari banjir maupun genangan yang terjadi. 
Melihat kondisi MAN 1 Sumbawa Besar yang saat ini masih sering dijumpai genangan air di saat hujan, maka saya sebagai peneliti merasa terpanggil untuk mencegah dan mengatasinya dengan pembuatan sumur resapan dan Lubang Resapan Biopori (LRB). Diharapkan dengan adanya sumur resapan dan biopori, maka genangan air saat hujan dapat diminimalisir.

Lokasi penelitian ini terletak di MAN 1 Sumbawa Besar,jalan kepiting kelurahan seketeng kecamatan Sumbawa kabupaten Sumbawa.

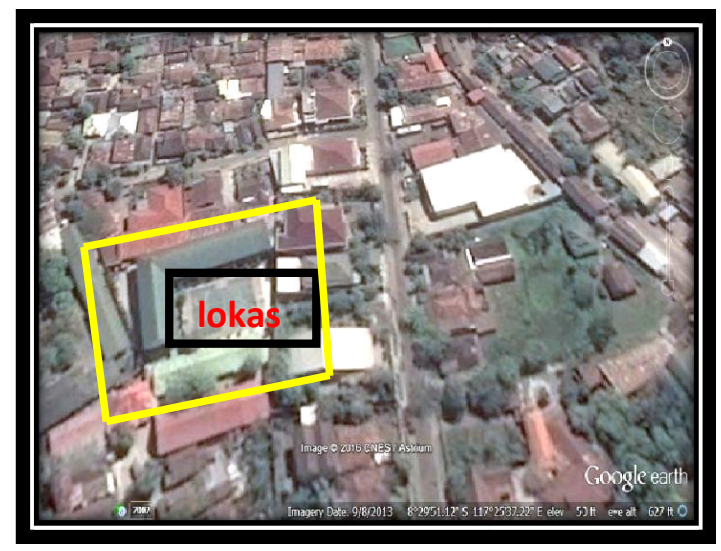

Gambar 01.

Lokasi Penelitian (geoogle earth, 2016)

Adapun lokasi bisa dilihat pada gambar 01 di bawah ini.

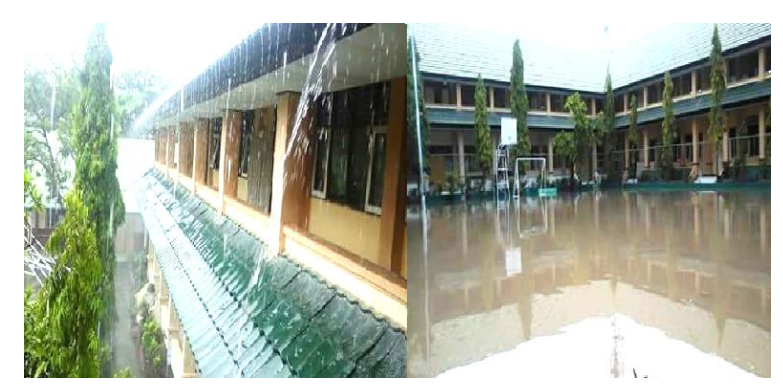

Gambar 02.

Kondisi halaman MAN 1 pada saat hujan.

(Visual Trash, 2016)

\section{KAJIAN PUSTAKA}

Hidrologi adalah ilmu yang yang bersifat menafsirkan. Melakukan percobaan dibatasi oleh ukuran kejadian di alam, yang diteliti sederhana saja dengan akibat yang bersifat khusus. Persyaratan mendasarnya berupa data yang diamati dan diukur mengenai semua segi pencurahan, pelimpasan, penelusan, pengaliran sungai, penguapan dan seterusnya. (E.M.Wilson, 1993:1)

Sumur resapan merupakan sumur atau lubang pada permukaan tanah yang dibuat untuk menampung air hujan agar dapat meresap ke dalam tanah. Sumur resapan ini kebalikan dari sumur air minum. Sumur resapan merupakan lubang untuk memasukkan air ke dalam tanah, sedangkan sumur air minum berfungsi untuk menaikkan air tanah ke permukaan. Dengan demikian konstruksi dan kedalamannya berbeda. Sumur resapan digali dengan kedalaman di atas muka air tanah. Sumur air minum digali lebih dalam lagi atau di bawah muka air tanah. (Kusnaedi, 2011:6)

Biopori merupakan ruang atau pori dalam tanah yang dibentuk oleh makhluk hidup, seperti mikroorganisme tanah dan akar tanaman. Bentuk biopori menyerupai liang (terowongan kecil) di dalam tanah dan bercabangcabang dan sangat efektif untuk menyalurkan air dan udara ke dalam tanah. Liang pori terbentuk oleh adanya pertumbuhan dan perkembangan akar tanaman, serta aktivitas fauna tanah seperti cacing tanah, rayap dan semut di dalam tanah (Brata, 2008).

Lubang Resapan Biopori (LRB) adalah lubang yang digali vertikal ke dalam tanah berbentuk silindris berdiameter $10 \mathrm{~cm}$, dengan kedalaman \pm 1 meter (tidak melebihi muka air tanah). Lubang resapan digali dengan menggunakan bor biopori agar diameter yang dihasilkan akan seragam (Brata, 2008).

Data hidrologi adalah kumpulan keterangan atau fakta mengenai fenomena hidrologi, seperti besarnya : curah hujan, temperatur, penguapan, lamanya penyinaran matahari, kecepatan angin, debit sungai, tinggi muka air sungai, kecepatan aliran, konsentrasi sedimen sungai akan selalu berubah terhadap waktu. (Soewarno, 1995).

\section{METODOLOGI PENELITIAN}

Penelitian tentang perencanaan sumur resapan dan lubang resapan biopori sebagai alternative penanggulangan banjir di Madrasah Aliyah Negeri (MAN) 1 Sumbawa Besar ini menggunakan metode penelitian deskriptif kuantitatif. Penelitian deskriptif merupakan 
dasar bagi semua penelitian. Penelitian deskriptif dapat dilakukan secara kuantitatif agar dapat dilakukan analisis statistik.

Setelah mengidentifikasi dari permasalahan yang ada di lapangan maka langkah selanjutnya adalah mencari data pendukung untuk menyelesaikan permasalahan tersebut. Data yang digunakan dalam penulisan ini adalah data primer dan data sekunder. Data primer merupakan data yang diperoleh secara langsung. Sedangkan data sekunder merupakan data yang diperoleh secara tidak langsung berupa catatan maupun hasil penelitian dari pihak lain. Diantaranya data Luas lahan, Tinggi Genangan,Data curah hujan, Permeabilitas tanah, Tekstur tanah

Metode yang digunakan untuk menghitung curah hujan adalah metode metode Mononobe. Caranya adalah dengan menjumlahkan curah hujan pada tiap stasiun kemudian membaginya dengan jumlah stasiun yang ada. Metode ini masih memiliki banyak kelemahan karena tidak memasukkan pengaruh topografi. Metode ini dapat digunakan dengan hasil memuaskan apabila daerahnya datar dan penempatan alat ukur tersebar merata, serta curah hujan tidak bervariasi banyak dari harga tengahnya.

Metode Mononobe: (I Made Kamiana, 2012:74)

$$
\bar{R}=\underline{R 1+R 2+R 3+\ldots R n}
$$

$\mathrm{n}$

Dimana :

$\overline{\mathrm{R}} \quad=$ curah hujan rata-rata $(\mathrm{mm})$

$\mathrm{R}=$ Tinggi curah hujan di stasiun I ( $\mathrm{mm}$ )

$\mathrm{A}_{1}-\mathrm{An}=$ luas daerah pengaruh stasiun $\mathrm{I}(\mathrm{Km})$

Pengujian konsistensi dari serangkaian data ini dapat dilakukan dengan menggunakan kurva massa (mass curve) yaitu suatu grafik yang menggambarkan komulatif dari serangkaian data hujan stasiun yang di uji sebagai ordinat, dan kumulatif dari rangkaian data hujan beberapa stasiun sekitar sebagai absis, kemudian koordinatnya diplotkan. Dari pengujian ini data yang tidak konsisten akan Nampak dari penyimpangan garisnya terhadap garis lurus. Dalam hal ini dianggap bahwa data dari stasiun hujan yang digunakan sebagai referensi yang berada di sekitarnya merupakan data yang konsisten, oleh karena itu pengujian ini sering menimbulkan keraguan, karena adanya kemungkinan tidak konsistensinya stasiun referensi.

Untuk itu perlu dilakukan tes statistik untuk menguji konsistensi data, yaitu dengan menggunakan data dari stasiun itu sendiri. Tes statistik yang diperhitungkan menggunakan metode RAPS (Rescaled Adjusted Partial Sums). Cara ini didasarkan pada rumusan sebagai berikut (I Made Kamiana, 2012 : 21)

$$
\begin{aligned}
\mathbf{S k} * * & =\frac{\mathbf{S k} * *}{\mathbf{D Y}} \\
\mathbf{K} & =1, \ldots \ldots . \mathbf{n}
\end{aligned}
$$

Dengan Sk* adjusted partial sums atau kumulatif penyimpangannya dari rata - rata dirumuskan sebagai berikut :

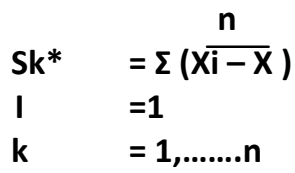

Dan DY adalah Deviasi standar dari sampel yang dirumuskan dengan :

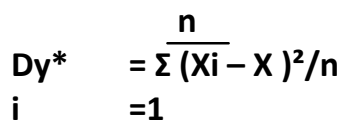

Dengan :

$\mathrm{n} \quad$ = Jumlah Data Hujan

$\mathrm{Xi} \quad=$ Data Curah Hujan

$\mathrm{X} \quad=$ Rerata Curah Hujan

$\mathrm{Sk}^{*}, \mathrm{Sk}^{* *}$, Dy = Nilai Statistik

Nilai statistik dari $Q$ adalah :

$\mathbf{Q}=$ maks $|\mathbf{S k} * *|$

$0<k<n$

Intensitas hujan atau intensitas hujan rencana dapat dikatakan sebagai ketingian atau kederasan hujan persatuan waktu, biasanya dalam satuan ( $\mathrm{mm} / \mathrm{jam})$ atau (cm/jam).

\section{Rumus mononobe :}

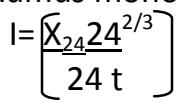

Dimana :

I = Intensitas curah hujan ( $\mathrm{mm} / \mathrm{jam}$ )

$\mathrm{X}_{24}=$ curah hujan maksimum harian (selama 24 jam) (mm)

$\mathrm{t} \quad=$ lamanya hujan (24 jam) (mm)

Rumus Van Breen :

$$
\mathrm{I}=\frac{90 \% \times \mathrm{X}_{24}}{4}
$$


Dimana :

$\mathrm{I}=$ Intensitas curah hujan ( $\mathrm{mm} / \mathrm{jam}$ )

$\mathrm{X}_{24}=$ curah hujan maksimum harian (selama 24 jam) (mm)

Koefisien Aliran Permukaan (C) didefinisikan sebagai nisbah antara puncak aliran permukaan terhadap intensitas hujan. Perkiraan atau pemilihan nilai $C$ secara tepat sulit dilakukan, karena ini antara lain bergantung dari : (I Made Kamiana, 2012 : 84)

Waktu konsentrasi adalah waktu yang diperlukan untuk mengalirkan air dari titik yang paling jauh pada daerah aliran ke titik control yang ditentukan di bagian hilir suatu saluran.

Untuk menghitung waktu konsentrasi dapat dihitung dengan rumus kirpich.(I Made Kamiana,2012:83)

$$
\text { tc }=\frac{0,87 \times L^{2} 0,385}{1000 \times S}
$$

Keterangan rumus :

tc $=$ Waktu konsentrasi (jam)

$\mathrm{L}=$ Panjang lintasan air dari titik terjauh ke titik yang ditinjau

$\mathrm{S}=$ Kemiringan rata-rata daerah lintasan

Debit rencana adalah debit dengan periode ulang tertentu $(\mathrm{T})$ yang diperkirakan melalui suatu sungai atau bangunan air. Karena data hujan dan karakteristik daerah aliran tersedia maka rumus yang dipakai adalah metode rasional: ( I Made Kamiana, 2012 :7).

\section{$Q=0,278$ C. I. A}

Dengan :

$\mathrm{Q}=$ Debit puncak limpasan permukaan $\left(\mathrm{m}^{3} /\right.$ det $)$

$A=$ Luas daerah pengaliran $\left(\mathrm{m}^{2}\right)$

$\mathrm{I} \quad=$ Intensitas hujan ( $\mathrm{mm} / \mathrm{jam})$

$\mathrm{C}=$ Koefisien pengaliran

\section{Perencanaan Sumur Resapan}

1. Volume Sumur Resapan

Volume sumur resapan dapat dihitung menggunakan rumus volume tabung sebagai berikut : (Rian Hidayat, 2013 : 39)
$V=\left(1 / 4 \times \pi \times d^{2}\right) \times h$

Keterangan :

$\mathrm{V}=$ Volume sumur resapan $(\mathrm{m} 3)$

$\mathrm{d}=$ diameter sumur resapan $(\mathrm{m})$

$\mathrm{h}=$ Kedalaman sumur resapan $(\mathrm{m})$

2. Jumlah Sumur Resapan

$\mathrm{n}=\mathrm{Q} /$ Vol sumur resapan

Dimana :

$\mathrm{n}=$ jumlah sumur resapan

$\mathrm{Q}=$ Debit banjir

Menghitung Dimensi LRB

Volume LRB dapat dihitung menggunakan rumus volume tabung sebagai berikut : (Rian Hidayat, 2013 : 39)

$$
\begin{aligned}
& V=\left(1 / 4 \times \pi \times d^{2}\right) \times h \\
& \text { Keterangan : } \\
& V=\text { Volume LRB }(\mathrm{m} 3) \\
& d=\text { diameter LRB }(\mathrm{m}) \\
& \mathrm{h}=\text { Kedalaman LRB }(\mathrm{m})
\end{aligned}
$$

Jumlah LRB yang disarankan Jumlah lubang yang perlu dibuat dapat dihitung dengan menggunakan persamaan :

$$
n=\frac{I x L}{v}
$$

Keterangan :

$\mathrm{n}$ : Jumlah Lubang Resapan Biopori

$\mathrm{I}$ : Intensitas hujan ( $\mathrm{mm} / \mathrm{jam})$

$\mathrm{L}$ : Luas bidang kedap air (m2)

v : Laju rembesan air (liter/jam)

\section{PEMBAHASAN}

A. Pengumpulan Data

Peta lokasi penakar hujan Sumbawa digunakan untuk mengetahui letak stasiun curah hujan. Dalam hal ini data hujan yang digunakan adalah data hujan harian. Dalam penelitian ini stasiun hujan yang digunakan adalah stasiun Sumbawa dan stasiun Unter Iwes.

Data yang digunakan adalah data sekunder berupa data hujan dengan waktu pengamatan 10 tahun yaitu dari tahun 20062015. Untuk uji kepanggahan data digunakan data hujan tahunan, sedangkan untuk analisis 
IDF digunakan data hujan jam-jaman. Data hujan ini diperoleh dari Dinas Pertanian dan Holtikultura Kabupaten Sumbawa.

Jenis tanah dilokasi penelitian berdasarkan teori di kajian pustaka tentang tekstur tanah tentang ciri-ciri tanah lanau yaitu bahan yang merupakan peralihan antara lempung dan pasir halus.

Berdasarkan ciri-ciri dari jenis tanah, maka tanah di lokasi penelitian termasuk jenis tanah lanau. Maka permeabilitas tanah di lokasi penelitian berdasarkankoefisien permeabilitas tanah lanau adalah 0,001-0,00001 $\mathrm{Cm} / \mathrm{dt}$. Artinya layak untuk dibangun sumur resapan.

Luas lahan di lokasi MAN 1 Sumbawa adalah $3.997 \mathrm{~m} 2$.

Tinggi genangan di lokasi MAN 1 Sumbawa adalah $20-50 \mathrm{~cm}$.

\section{B. Analisis Hidrologi}

Data hujan yang digunakan adalah data hujan harian dari hasil pengamatan 2 stasiun hujan yang berpengaruh pada lokasi MAN 1 Sumbawa yakni stasiun hujan Sumbawa dan stasiun hujan Unter Iwes. Data curah hujan yang digunakan yaitu data curah hujan tahun 2006 s/d 2015.

Karena data hujan jangka pendek tidak tersedia, maka peneliti menggunakan rumus Van breen. Dalam rumus van breen, durasi hujan harian diasumsikan 4 jam, dan besarnya hujan harian efektif adalah $90 \%$ dari hujan harian maksimum.

$$
\begin{aligned}
& \text { Rumusnya adalah : } \\
& \mathrm{I}=\frac{90 \% \times \times 24}{4}
\end{aligned}
$$

Besar hujan rancangan untuk kala ulang 2 tahun adalah $\times 2=33.55 \mathrm{~mm} / \mathrm{jam}$. untuk kala ulang 5 tahun adalah $\times 5=178.72 \mathrm{~mm}$ untuk kala ulang 10 tahun adalah $\times 10=$ $312.22 \mathrm{~mm}$

Hitungan intensitas hujan untuk kala ulang 2, 5 dan 10 tahun

$$
\begin{aligned}
12 & =\frac{90 \% \times \times 24}{4}=\frac{90 \% \times 266.129}{4} \\
& =7.594 \mathrm{~mm} / \mathrm{jam} \\
& =\frac{90 \% \times \times 24}{4}=\frac{90 \% \times 178,718}{4} \\
& =40.212 \mathrm{~mm} / \mathrm{jam}
\end{aligned}
$$

$$
\begin{aligned}
I 10 & =\frac{90 \% \times \times 24}{4}=\frac{90 \% \times 312,21}{4} \\
& =70.250 \mathrm{~mm} / \mathrm{jam}
\end{aligned}
$$

Berdasarkan penggunaan lahan di MAN 1 Sumbawa, maka koefisien adalah sebagai berikut :

Bangunan multiunit terpisah dengan luas $1.696 \mathrm{~m}^{2}$ dan taman tempat bermain dengan luas $600 \mathrm{~m}^{2}$. Jadi untuk menghitung kooefisien dihitung dengan rumus :

$$
\begin{aligned}
& C=\frac{C 1 . A 1+C 2 \cdot A 2+\ldots \ldots . .+C n \cdot A n}{A 1+A 2+\ldots \ldots \ldots+A n} \\
& C=0,4 \times 1696+0,35 \times 600 \\
& 1696+600 \\
& C=0,387
\end{aligned}
$$

Panjang lintasan air dari titik terjauh ke titik yang ditinjau $(\mathrm{L})=42,2$ Meter

Kemiringan rata-rata $(S)=2 \%$ Karena kondisi lahan datar berdasarkan tabel 2.9. Rumus menghitung waktu konsentrasinya adalah :

$$
\begin{aligned}
\text { TC } & =\frac{0,87 \times \mathrm{L}^{20,385}}{1000 \times \mathrm{S}} \\
& =\frac{0,87 \times 42.2^{20,385}}{1000 \times 0,02} \\
& =0.85 \mathrm{jam} \text { atau } 51 \text { menit }
\end{aligned}
$$

Perhitungan debit banjir rancangan dihitung dengan menggunakan metode rasional :

$$
\begin{aligned}
& \text { Koefisien limpasan } \quad=0,387 \\
& \text { Intensitas hujan ( I) } \quad=40.212 \mathrm{~mm} / \mathrm{jam} \\
& \text { Luas wilayah (A) } \quad=1.701 \mathrm{~m}^{2} \\
& \text { Sehingga diperoleh debit } Q=0,278 \text {. C.I. A } \\
& Q=0,278 \text {. C.I.A } \\
& =0,278 \cdot 0,387 \text {. } \\
& \text { 40,212. } \\
& =14,696 \mathrm{~m}^{3} / \mathrm{det}
\end{aligned}
$$

Besar debit banjir rancangan dalam kala ulang 5 tahun adalah 14,696 $\mathrm{m}^{3}$ / det. atau 14.696 liter.

Direncanakan penggunaan sumur resapan untuk meresapkan air hujan kedalam tanah, diasumsikan dimensi sumur resapan yang akan dipergunakan adalah :

diameter $(\mathrm{d}): 1,5 \mathrm{~m}$ dan tinggi $(\mathrm{h}): 2 \mathrm{~m}$

Volume sumur resapan : 
$V=\left(1 / 4 \times \pi \times d^{2}\right) \times h$

$V=\left(1 / 4 \times \times 3,14 \times 1,5^{2}\right) \times 2$

Volume sumur $=3,825 \mathrm{~m}^{3}$

Volume sumur $=3825$ liter

Jumlah sumur resapan yang dibutuhkan

$\mathrm{n}=\mathrm{Q}$ rancangan / Vol sumur

$\mathrm{n}=14.696$ liter $/ 3825$

$n=3,84 \cong 4$ buah

jadi jumlah sumur resapan yang dibutuhkan dikawasan MAN 1 Sumbawa Besar adalah sebanyak 4 buah.

Panjang kawasan yang mau ditempatkan sumur resapan adalah (P) 30 meterjarak antar sumur resapan (s)

(s) $=\mathrm{P} / \mathrm{n}$

(s) $=30 \mathrm{~m} / 4$

(s) $=7.5$ meter $\cong 7.5 \mathrm{~m}$

Jadi, sumur resapan dipasang dengan jarak antar sumur (s) : 7.5 meter

Dalam merencanakan sebuah LRB kita harus menentukan dulu dimensi LRB. Adapun dimensi lubang resapan biopori menurut (brata, 2008) adalah : diameter (d) : $10 \mathrm{~cm}=$ $0,1 \mathrm{~m}$ dan tinggi $(\mathrm{h}): 100 \mathrm{~cm}=1 \mathrm{~m}$

$$
\text { Volume LRB } \quad \begin{aligned}
\mathrm{V} & =\left(1 / 4 \times \pi \times \mathrm{d}^{2}\right) \times \mathrm{h} \\
\mathrm{V} & =\left(1 / 4 \times 3,14 \times 0.1^{2} \times 1\right. \\
\mathrm{V} & =0.00785 \mathrm{~m}^{3} \\
\mathrm{~V} & =7.85 \text { liter }
\end{aligned}
$$

Luas bidang kedap yang mau ditempatkan LRB adalah $74 \mathrm{~m}^{2}$ dan laju resap air adalah 245 liter /jam.

Jumlah LRB yang perlu dibuat dapat dihitung dengan rumus :

$$
\begin{aligned}
\mathrm{n} & =\frac{\mathrm{I} \times \mathrm{L}}{\mathrm{V}} \\
& =\frac{40.212 \mathrm{~mm} / \text { jam } \times 74 \mathrm{~m}^{2}}{245} \\
& =12.14 \text { buah } \cong 12 \text { buah }
\end{aligned}
$$

Jarak antar LRB $=\mathrm{L} / \mathrm{n}$

Jarak antar LRB $=74 / 12=6,16$ meter

$$
\cong 6 \text { meter }
$$

Jadi, jumlah LRB yang dibutuhkan adalah 12 buah dengan jarak 6 meter.

Untuk perencanaan sumur resapan yaitu menggunakan buis beton dengan diameter 1,5 m, dan ketinggiannya $2 \mathrm{~m}$. Untuk gambarnya bisa dilihat pada gambar dibawah ini :

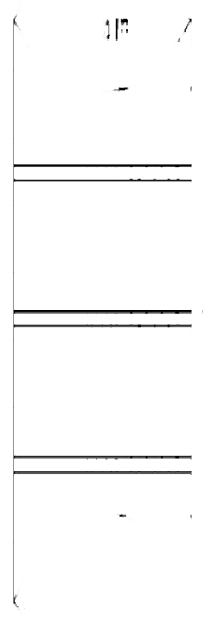

Gambar 03. Rencana sumur resapan

Untuk perencanaan LRB (Lubang Resapan Biopori) menggunakan pipa paralon dengan diameter $10 \mathrm{~cm}$ dan ketinggian 100 cm. Untuk gambarnya bisa dilihat pada gambar dibawah ini :

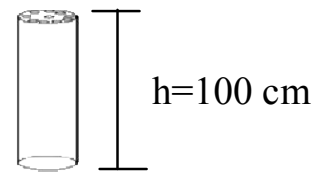

Gambar 04. Rencana LRB

\section{PENUTUP}

Hasil dari perencanaan sumur resapan diperoleh dimensi sumur resapan dengan diameter 1,5 $\mathrm{m}$ dan kedalaman $2 \mathrm{~m}$ dengan jumlah sumur resapan sebanyak 4 buah dengan jarak 7.5 meter. Dengan perencanaan 4 buah sumur resapan pada lahan MAN 1 Sumbawa akan bisa menanggulangi genangan yang terjadi pada musim hujan.

Hasil dari perencanaan untuk LRB diperoleh dimensi dengan diameter $10 \mathrm{~cm}$ $(0,1 \mathrm{~m})$ dan kedalaman $100 \mathrm{~cm}(1 \mathrm{~m})$ dengan jumlah pekerjaan LRB sebanyak 12 buah dengan jarak 6 meter. Dengan perencanaan 12 buah LRB bisa melindungi system air tanah (ground water system) pada kawasan MAN 1 Sumbawa Besar. 
DAFTAR PUSTAKA

Brata, Kamir R dan Anne Nelistya, 2008. Lubang Resapan Biopori, Bogor.

Brata K.R dan Anne Nelistya (2011). Lubang Resapan Biopori. Depok : Swadaya.

Brata, K.R., Nelistya A., 2008. Lubang Resapan Biopori, Penebar Swadaya, Jakarta.

Buckman, H. 0. dan N. C. Brady. 1982. IImu Tanah (terjemahan Soegiman). Bhratara Karya Aksara, Jakarta.

Foth, H.D., 1984. Dasar - Dasar Ilmu Tanah. Edisi VI. Erlangga, Jakarta.

Hanafiah, A.K., 2005. Dasar - Dasar IImu Tanah. Raja Grafindo Persada, Jakarta.

Hardjowigeno. 2003. Ilmu Tanah. PT Media Tama Sapama. Jakarta.

Kamiana Made, I. 2012. Teknik Perhitungan Debit Rencana Bangunan Air. Yogyakarta : Graha Ilmu

Kesuma, R. Wijaya. 2012. Studi Pemaksimalan Resapan Air Hujan dengan Lubang Resapan Biopori Untuk Mengatasi Banjir (Studi Kasus : Kecamatan Dayeuh Kolot Kabupaten Bandung). ITB. Bandung

Kusnaedi. 2011. Sumur Resapan untuk Pemukiman Perkotaan dan Pedesaan. Jakarta: Penebar Swadaya.

Soewarno. 1995. Hidrologi Aplikasi Metode Statistik untuk Analisis Data. Jilid 1.

Suripin. 2004. Sistem Drainase Perkotaan yang Berkelanjutan. Yogyakarta: Andi.

Wilson, E.M.1993. Hirologi Teknik. Bandung : ITB Bandung. 